\title{
Effectiveness of physician-targeted interventions to improve antibiotic use for respiratory tract infections
}

\begin{abstract}
Background

Antibiotic use and concomitant resistance are increasing. Literature reviews do not unambiguously indicate which interventions are most effective in improving antibiotic prescribing practice.
\end{abstract}

\section{Aim}

To assess the effectiveness of physician-targeted interventions aiming to improve antibiotic prescribing for respiratory tract infections (RTIs) in primary care, and to identify intervention features mostly contributing to intervention success.

\section{Design and setting}

Analysis of a set of physician-targeted interventions in primary care.

\section{Method}

A literature search (1990-2009) for studies describing the effectiveness of interventions aiming to optimise antibiotic prescription for RTIS by primary care physicians. Intervention features were extracted and effectiveness sizes were calculated. Association between intervention features and intervention success was analysed in multivariate regression analysis.

\section{Results}

This study included 58 studies, describing 87 interventions of which $60 \%$ significantly improved antibiotic prescribing; interventions aiming to decrease overall antibiotic prescription were more frequently effective than interventions aiming to increase first choice prescription. On average, antibiotic prescription was reduced by $11.6 \%$, and first choice prescription increased by $9.6 \%$. Multiple interventions containing at least 'educational material for the physician' were most often effective. No significant added value was found for interventions containing patientdirected elements. Communication skills training and near-patient testing sorted the largest intervention effects.

\section{Conclusion}

This review emphasises the importance of physician education in optimising antibiotic use. Further research should focus on how to provide physicians with the relevant knowledge and tools, and when to supplement education with additional intervention elements. Feasibility should be included in this process.

\section{Keywords}

antibiotics; primary health care; education

respiratory tract infection.

\section{INTRODUCTION}

Misuse of antibiotics is an urgent, progressive and worldwide public-health problem. Overuse of antibiotics in general and excessive use of broad spectrum antibiotics, have contributed to development of antimicrobial resistance. ${ }^{1}$ Non-indicated use of antibiotics is furthermore related to unnecessary exposure to adverse effects, costs and patients' re-consultation. ${ }^{2,3}$ There is growing concern that therapeutic options become limited if resistance rates continue to rise. The most effective strategy for combating antimicrobial resistance is decreasing antibiotic use. ${ }^{4}$

The vast majority of antibiotics are used by primary care patients, mainly for respiratory tract infections (RTIs): otitis media, sinusitis, rhinitis, tonsillitis, pharyngitis, and bronchitis. ${ }^{5}$ RTIs are mostly viral and self-limiting, and therefore treatment effects of antibiotics are modest to negligible. ${ }^{6,7}$ Nonetheless, antibiotics are often prescribed for RTIs, ${ }^{8}$ while for the majority of patients watchful waiting for the disease to run its natural course is the best approach.

In improving antibiotic use, primary care physicians and their patients are potential targets for intervention. For physicians, many guidelines have been published on appropriate treatment of RTIs. These appeared not to be sufficient enough to decrease antibiotic prescribing; implementing guidelines into daily clinical

AW van der Velden, $\mathrm{PhD}$, assistant professor; EJ Pijpers, MSc, PhD student; MM Kuyvenhoven, PhD, associate professor; TJM Verheij, MD, PhD MRCGP, professor of general practice, Julius Center for Health Sciences and Primary Care, University Medical Center Utrecht, Utrecht, the Netherlands. SKG Tonkin-Crine, MSc, research fellow; P Little, MD, MRCP, FRCGP, professor of primary care research, Primary Care and Population Sciences, Faculty of Medicine, University of Southampton, Southampton. Address for correspondence Alike W van der Velden, Julius Center for Health practice is hampered by factors like habits, lack of knowledge, and patients' behaviour. ${ }^{9-11}$

Numerous interventions have been carried out, mainly in Europe and the US, with the aim to improve antibiotic prescribing practice. These are summarised in four qualitative and semi-quantitative reviews. ${ }^{12-15}$ However, there is still ambiguity whether multiple interventions are more effective than focused clinician education. In particular, the additive effect of audit/ feedback, patient information material, involving other healthcare providers, remains unclear. By clarifying which intervention features mostly benefit, the complexity of implementing comprehensive interventions may be reduced.

The most recent review identified studies up to $2006,{ }^{15}$ but there have been important studies since. As problems related to antibiotic overuse are still increasing there is a need for insight in effectiveness of interventions. As part of the European CHAMP project (Changing behaviour of Healthcare professionals And the general public towards a More Prudent use of antimicrobial agents) the study analysed an updated set of physician-targeted interventions. The study thereby aims to assess overall effectiveness and identify intervention features mostly contributing to a positive intervention outcome. The set contains a broad range of study designs and is limited to interventions concerning RTIs.

Sciences and Primary Care, University Medical Center Utrecht (STR 6.103), Heidelberglaan 100, 3584 CX Utrecht, the Netherlands.

E-mail: a.w.vanderveldendumcutrecht.nl Submitted: 4 July 2012; Editor's response: 28 July 2012; final acceptance: 29 August 2012. CBritish Journal of General Practice This is the full-length article (published online 26 Nov 2012) of an abridged version published in print. Cite this article as: Br J Gen Pract 2012; DOI: 10.3399/bjgp12X659268 


\section{How this fits in}

Antibiotics are often overprescribed for respiratory tract infections (RTIs). This literature overview shows that physician education is effective in decreasing antibiotic use for RTIs. As multiple interventions were most often effective, education or educational material needs to be supplemented with another intervention element. Addition of patient information did not significantly increase effectiveness rates. Communication skills training for physicians is a promising intervention element to intensify education on prudent use of antibiotics.

\section{METHOD}

\section{Search and screening}

A search in MEDLINE, EMBASE, and the Cochrane Library was performed from January 1990 to July 2009, using several combinations of the keywords land synonyms of): antibiotic, primary care, intervention, respiratory tract infection, and the specific RTI diagnoses. In addition, reference lists were screened. Inclusion criteria were: an 'intervention' primarily targeted at 'physicians' in a 'primary care' setting aiming to 'improve antibiotic prescription' for 'RTIs', conducted in a 'high-income country', presenting a 'standardised outcome' of 'ffirst choice) prescription' measured in 'defined daily dosage, prescriptions or rates', and 'published in the English language'.

Studies were screened on relevance using title, keywords, and abstract, and subsequently using the full texts, independently by two reviewers; disagreement was resolved by consensus or by arbitration of a third person. The main reasons for exclusion were a lack of standardised outcomes or a clear description of intervention features.

\section{Data extraction}

Study data were extracted using a structured form lbased on the Cochrane Data Collection Checklist of the Effective Practice and Organisation of Care group) $)^{16,17}$ containing the following domains: study design, intervention characteristics (type -single/multiple/multi-target-, targets -physician, patients, others-, patients' age, setting, targeted diagnoses), the elements the intervention was composed of, and outcome parameters.

Intervention elements were categorised into: distribution of educational material ffor the physician, patients presenting with a $\mathrm{RTI}$, all practice patients, or the general public), educational meetings, consensus procedure, educational outreach visits, local opinion leaders, near-patient testing, audit and feedback, reminders, financial incentives, and communication skills training.

\section{Analyses}

Intervention effectiveness was calculated in terms of percentages: 1) the difference of differences ( $\delta \delta$ ) for interventions with a before and after measurement and a control group, 2) the difference ( $\delta$ ) for interventions with a before and after measurement without a control group, or 3) the difference in after measurement for interventions with a control group but without a before measurement.

For transparency and logistic regression analysis, effectiveness was categorised into 'plus' la statistically significant decrease in total prescription, or increase in first choice prescription), 'plus/minus' la nonsignificant decrease in prescription, or increase in first choice prescription), or 'minus' (interventions without an effect, or with a negative effect). Associations between effectiveness ('plus' interventions versus the rest) and intervention features were analysed in logistic regression analysis; characteristics and elements used in at least 15 interventions were used. Statistics were calculated using SPSS (version 17.0).

\section{RESULTS}

\section{Description of included interventions}

This review comprises 58 studies, ${ }^{18-75}$ describing a total of 87 interventions aiming to optimise antibiotic prescription for RTIs. The designs used most often were a controlled before after design $(41 \%)$ and a randomised controlled trial (29\%). The remaining studies were RCTs without baseline measurements, or had an interrupted time series-like design with one before and one after measurement.

Of the interventions, $59(68 \%)$ aimed to decrease total prescription of antibiotics, and $28(32 \%)$ to increase prescription of first choice antibiotics, $71 \%$ were targeted at more than one RTI diagnosis, $77 \%$ were multiple lintervention consisting of more than one element), and $40 \%$ targeted other groups besides the physician. The 87 interventions comprised 281 intervention elements (Table 1); educational material for the physician ( $n=61)$, educational meeting ( $n=49)$, and audit/feedback ( $n=32)$ were most often used.

\section{Effectiveness of the interventions}

Overall, $60 \%$ of the interventions significantly 


\section{Table 1. Frequencies of intervention elements used within the 87 interventions ( $n=281)$}

\begin{tabular}{lcc} 
Intervention element & Frequency & $\%^{\mathrm{a}}$ \\
\hline Educational material for the physician & 61 & 70 \\
\hline Educational meeting & 49 & 56 \\
\hline Audit and feedback & 32 & 37 \\
\hline Educational outreach visit & 24 & 28 \\
\hline Educational material for RTI patients & 21 & 24 \\
\hline Educational material for practice patients & 17 & 20 \\
\hline Educational material for general public & 15 & 17 \\
\hline Reminders & 12 & 14 \\
\hline Consensus procedure & 9 & 10 \\
\hline Communication skills training & 8 & 9 \\
\hline Near-patient testing & 7 & 8 \\
\hline Local opinion leader & 6 & 7 \\
\hline Financial incentives & 6 & 7 \\
\hline Other & 14 & 16
\end{tabular}

a\% of interventions containing the particular element. ${ }^{b}$ For example, national policy, group discussions between physicians and patients, visiting a microbiology lab.

Table 2. Proportion of effective interventions $(n=87)$

\begin{tabular}{lccc} 
& $\mathbf{A B}$ & $\mathbf{F C}$ & Total \\
\cline { 2 - 4 } Effectiveness category & $n=59$ & $n=28$ & $n=87$ \\
\hline Plus & $43(73 \%)$ & $9(32 \%)$ & $52(60 \%)$ \\
\hline Plus/minus & $12(20 \%)$ & $17(61 \%)$ & $29(33 \%)$ \\
\hline Minus & $4(7 \%)$ & $2(7 \%)$ & $6(7 \%)$
\end{tabular}

$A B=$ decreasing total antibiotic prescription. $F C=$ increasing first choice prescription. Plus = a statistically significant decrease in total prescription or increase in first choice prescription. Plus/minus = a non-significant decrease in total prescription or increase in first choice prescription. Minus = interventions without an effect or with a negative effect.
Associations between effectiveness rates and intervention features

Within the 59 interventions aiming to decrease overall prescription for RTIs, the associations of various intervention features with effectiveness are shown in Table 4. Multiple interventions were more frequently effective than interventions using one element lodds ratio [OR] 6.5). With respect to the most often effective intervention element, only educational material for the physician showed an independent association with a positive intervention outcome (OR 5.5).

As multiple interventions showed to be most often effective, various combinations of elements were tested for their combined effectiveness rate. Only the combination educational material for the physician with educational meeting yielded significance (OR 3.5; $95 \% \mathrm{Cl}=1.2$ to 10). In a multipletarget intervention, combining physician with patient education, a non-significant added value was found from adding educational material for patients (OR 5.8; $95 \% \mathrm{Cl}=1-35$ )

\section{DISCUSSION}

\section{Summary}

Interventions aimed at reducing overall prescription were more frequently effective (73\%) and had higher effectiveness (-11.6\%) than interventions aimed at increasing first choice prescription $132 \%$ of interventions were effective, with a mean increase of 9.6\%). Multiple interventions, which contained at least educational material for the physician, were most often effective. Non-significant added values were found for interventions which, in addition to physician education, contained information material for patients.

\section{Strengths and limitations}

This broad overview of physician-targeted interventions to improve antibiotic prescribing for RTIs is part of the CHAMP project. The aim of CHAMP was to review all available evidence of the effectiveness of interventions, campaigns, and projects, to obtain a complete picture of how to promote prudent antibiotic use. In propagating initiatives to restrict antibiotic use, such combined insight is pivotal in designing the most effective intervention.

A potential pitfall of making searches as complete as possible by including a broad variety of study designs is decreasing overall quality. The study rated the quality of all included studies, ${ }^{76}$ which offered the possibility to limit the analyses to moderate and high quality interventions; this did not 


\section{Table 3. Effectiveness outcomes of the interventions ( $n=87)$}

\begin{tabular}{lcccc} 
Outcome & Total AB, mean (range), $\%$ & $\boldsymbol{n}$ & First choice, mean (range), $\%$ & $\boldsymbol{n}$ \\
\hline$\delta \delta$ & $-8.7(-27$ to 18.8$)$ & 33 & $9.2(-2$ to 27.2$)$ & 15 \\
\hline$\delta$ & $-12.3(-37$ to 4.3$)$ & 16 & $11.1(-5$ to 41$)$ & 11 \\
\hline diff i-a & $-20.3(-72$ to -1$)$ & 10 & $3.6(2$ to 5.1$)$ & 2 \\
\hline
\end{tabular}

$\delta \delta=$ difference of differences for interventions with a before and after measurement and a control group. $\delta=$ difference for interventions with a before and after measurement without a control group. diff $i-a=$ difference in after measurement for interventions with a control group but without a before measurement.

\section{Table 4. Associations between intervention features and effectiveness rates $(n=59)$}

\begin{tabular}{|c|c|c|c|}
\hline Intervention features & $n$ & Crude OR $(95 \% \mathrm{CI})$ & $\operatorname{AOR}(95 \% \mathrm{CI})$ \\
\hline More RTI diagnoses ${ }^{a}$ & 42 & $1.7(0.6$ to 4.9$)$ & $2.5(0.7$ to 8.9$)$ \\
\hline More targets ${ }^{b}$ & 28 & $1.7(0.7$ to 4.7$)$ & $1.4(0.4$ to 4.7$)$ \\
\hline Multiple intervention ${ }^{c}$ & 46 & $7.6(2.4$ to 24$)$ & $6.5(1.9 \text { to } 22)^{d}$ \\
\hline Educational material physician & 41 & $5.6(2$ to 16$)$ & $5.5(1.7 \text { to } 18)^{d}$ \\
\hline Educational meeting & 35 & $2.4(0.9$ to 6.4$)$ & 2.1 (0.7 to 6.8 ) \\
\hline Outreach visit & 16 & 2.1 (0.6 to 6.8$)$ & $1.2(0.3$ to 4.5$)$ \\
\hline Educational material RTI patients & 15 & $1.9(0.6$ to 6.2$)$ & 0.8 (0.2 to 3.3$)$ \\
\hline Educational material practice patients & 16 & $1.9(0.6$ to 6.2$)$ & $1.4(0.4$ to 4.8$)$ \\
\hline Audit and feedback & 20 & $0.9(0.3$ to 2.4$)$ & 0.5 (0.2 to 1.8$)$ \\
\hline
\end{tabular}

$A O R=$ adjusted odds ratio. $O R=$ odds ratio. alnterventions targeted at more than one RTI diagnosis. ${ }^{b}$ Interventions targeting other groups besides the physician. Interventions consisting of more than one element. Multivariate regression analysis on interventions aiming to decrease overall antibiotic prescription. 'Statistical significance.

\section{Funding}

This work was supported by the Sixth Framework Programme of the European Commission in the context of the international collaborative CHAMP study: Changing behaviour of Healthcare professionals And the general public towards a More Prudent use of antimicrobial agents (reference: SP5A-CT-2007-044317).

\section{Provenance}

Freely submitted; externally peer reviewed.

\section{Competing interests}

The authors have declared no competing interests.

\section{Acknowledgements}

We thank our colleagues of the CHAMP consortium.

\section{Discuss this article}

Contribute and read comments about this article on the Discussion Forum: http://www.rcgp.org.uk/bjgp-discuss influence the conclusions (data not shown).

Other possible limitations of combined effectiveness calculations are language selection, publication bias, and selection bias of participants. The study cannot rule out that it missed interventions, those reported in non-English, or unpublished ones, for instance because of negative or unwanted results. It is likely that physicians participating in the included interventions were motivated to learn and change their behaviour. For a broader implementation towards a possibly less motivated population, presented effects may be an overestimation.

The set of included studies is homogeneous with respect to primary target group (physician), indication (RTI), setting (primary care), and aim loptimise antibiotic prescribing). However, the authors are aware of heterogeneity with respect to outcome variables, baseline prescribing, intensity of interventions, and geographic location. Especially due to differences in outcome measures lfor example, prescriptions or DDD per consultation, episode, patient, or inhabitant), absolute outcomes can not be compared in a meaningful way, and this study therefore focused on significance of effectiveness. Logistic regression on a binary outcome was used to identify the intervention features which are associated with intervention success, to provide insight for an effective basic intervention which can be broadly applied. Given the inclusion criteria, it is obvious that the majority of interventions use educational material and/ or meetings, of which only educational material appeared to be associated with intervention success. On the other hand, $40 \%$ of interventions also targeted patients with information material, and although effectiveness rates of these multitarget interventions were increased, this appeared not to be significant. This review thereby emphasises the central role of physician education and currently indicates less priority for extending these interventions with education directly delivered at patients.

\section{Comparison with existing literature}

Compared to the review of Arnold and Straus $^{12}$ this study specifically focused on physician-targeted interventions and RTIs, thereby identifying a newset of interventions; only 10 of the same studies appeared in both reviews. By the study's specific search, a more homogeneous set of studies is obtained which facilitates comparability and quantitative analyses. Arnold and Straus ${ }^{12}$ concluded that interventions aimed at reducing overall prescription are less often effective than interventions aimed at increasing first choice prescription, while this study found the opposite. However, they included some less effective interventions aimed at decreasing antibiotic prescription for asthma, diarrhoea, and skin infections.

The finding that multiple interventions are more often effective than single interventions is corroborated by others. However, two reviews concluded that multifaceted interventions, combining physician- and patient-targeted elements, are even more effective, and should be the approach to resolve antibiotic-related problems. ${ }^{12,13}$ the study's finding that targeting patients besides the physician did not significantly increase effectiveness rates is remarkable. One may expect that increasing patients' knowledge and awareness by offering information material, positively affect prescribing behaviour by decreasing pressure on physicians. A review of public campaigns to decrease antibiotic use suggested an effect of public education. ${ }^{77}$ However, all but one campaign targeted the public and physicians simultaneously, and it is therefore unclear whether the effects were 
attributable to behaviour of physicians, patients, or both. The results are in line with a meta-analysis concluding that patientoriented interventions have a very modest effect on antibiotic use, and that this effect was only due to delayed prescription by the physician. ${ }^{78}$

\section{Implications for clinical practice}

The conclusion that physician education is effective in decreasing antibiotic use relevant for primary care practice. However, the current situation shows that just delivering guidelines is not enough to restrict antibiotic prescribing. This review shows the need to intensify educational material by adding another element to create a multiple intervention. Which specific element to add will probably depend on the local situation, but various elements can be considered to adequately increase the impact of an intervention.

An educational meeting appeared more effective than audit/feedback and written patient information, but, on the other hand, is more labour intensive. Most studies indicate that patients are quite satisfied not receiving antibiotics as long as they are taken seriously, are being examined and get a proper explanation. ${ }^{78-80}$ The authors therefore hypothesise that it is more effective when patients receive explanation, reassurance, and antibiotic-related information from their own physician, specific to their own situation, instead of from written material. Time constraints and miscommunication between physician and patients about expectations of the consultation are thought to lead physicians to prescribe against their better judgement. ${ }^{81}$ Therefore, communication training, providing physicians with succinct and understandable arguments to communicate with their patients, should help to decrease antibiotic use. The few interventions using communication skills training appeared very effective. ${ }^{28,82}$ Another relatively new intervention element, near-patient testing, showed high effectiveness. ${ }^{26,28}$ Testing decreases diagnostic uncertainty of the physician, and concomitantly provides the physician with communication tools helping to explain treatment decisions to their patients.

These results emphasise the central role of physician education in decreasing antibiotic use. Ideally, a patient-centred element, teaching physicians how to efficiently communicate a clear take-home message and how to deal with patients' concerns and pressure, should be included. Research is needed on how to broadly deliver education, and to identify the essential elements for an effective and versatile intervention. 


\section{REFERENCES}

1. Goossens H, Ferech M, vander Stichele R, et al. Outpatient antibiotic use in Europe and association with resistance: a cross-national database study. Lancet 2005; 365(9459): 579-587.

2. Barlett JG. Antibiotic-associated diarrhoea. N Engl J Med 2002; 346(5): 334-339

3. Moore M, Little P, Rumsby K, et al. Effect of antibiotic prescribing strategies and an information leaflet on longer-term reconsultation for acute lower respiratory tract infection. Br J Gen Pract 2009; 59(567): 728-734.

4. Wise R. The relentless rise of resistance? J Antimicrob Chemother 2004; 54(2): 306-310.

5. Ong DS, Kuyvenhoven MM, van Dijk L, et al. Antibiotics for respiratory, ear and urinary tract disorders and consistency among GPs. J Antimicrob Chemother 2008; 62(3): 587-592.

6. Arroll B. Antibiotics for upper respiratory tract infections: an overview of Cochrane reviews. Respir Med 2005; 99(3): 255-261.

7. Smith SM, Fahey T, Smucny J, et al. Antibiotics for acute bronchitis. Cochrane Database Syst Rev 2004; (4): CD000245

8. Akkerman AE, Kuyvenhoven MM, van der Wouden JC, et al. Determinants of antibiotic overprescribing in respiratory tract infections in general practice. $J$ Antimicrob Chemother 2005; 56(5): 930-936.

9. Wensing M, van der Weijden T, Grol R. Implementing guidelines and innovations in general practice: which interventions are effective? Br J Gen Pract 1998; 48(427): 991-997.

10. Grimshaw JM, Thomas RE, MacLennan G, et al. Effectiveness and efficiency of guideline dissemination and implementation strategies. Health Technol Assess 2004; 8(6): iii-iv, 1-72.

11. Grol R, Grimshaw J. From best evidence to best practice: effective implementation of change in patients' care. Lancet 2003; 362(9391): 12251230.

12. Arnold SR, Straus SE. Interventions to improve antibiotic prescribing practices in ambulatory care. Cochrane Database Syst Rev 2005; 4: CD003539.

13. Gross PA, Pujat D. Implementing practice guidelines for appropriate antimicrobial usage: a systematic review. Med Care 2001; 39(8 Suppl 2): ॥1551169.

14. Steinman MA, Ranji SR, Shojania KG, et al. Improving antibiotic selection: a systematic review and quantitative analysis of quality improvement strategies. Med Care 2006; 44(7): 617-628

15. Ranji SR, Steinman MA, Shojania KG, et al. Interventions to reduce unnecessary antibiotic prescribing: a systematic review and quantitative analysis. Med Care 2008; 46(8): 847-862.

16. Effective Practice and organisation of care Group (EPOC). The data collection check list, section 2.1.1. http://epoc.cochrane.org/sites/epoc.cochrane.org/ files/uploads/datacollectionchecklist.pdf (accessed 6 Nov 2012).

17. Grimshaw J, McAuley LM, Bero LA, et al. Systematic reviews of the effectiveness of quality improvement strategies and programmes. Qual Saf Health Care 2003; 12(4): 298-303.

18. Anonymous. Medical audit in general practice. I: Effects on doctors' clinical behaviour for common childhood conditions. North of England Study of Standards and Performance in General Practice. BMJ 1992; 304(6840): 1480-1484.

19. Al-Khaldi YM, Al-Sharif Al, Al-Gelban KS, et al. Impact of national protocol on management of acute respiratory infections in children. Saudi Med J 2001; 22(9): 780-783.

20. Altiner A, Brockmann S, Sielk M, et al. Reducing antibiotic prescriptions for acute cough by motivating GPs to change their attitudes to communication and empowering patients: a cluster-randomized intervention study. $J$ Antimicrob Chemother 2007; 60(3): 638-644.

21. Bauchner $\mathrm{H}$, Marchant CD, Bisbee A, et al. Effectiveness of centers for disease control and prevention recommendations for outcomes of acute otitis media. Pediatrics 2006; 117(4): 1009-1017.

22. Belongia EA, Sullivan BJ, Chyou PH, et al. A community intervention trial to promote judicious antibiotic use and reduce penicillin-resistant Streptococcus pneumoniae carriage in children. Pediatrics 2001; 108(3): 575-583.

23. Berthiaume J, Chernicoff HO, Kim JJ, et al. Antibacterials for viral respiratory infections: results of a physician-based intervention in a predominantly preferred provider organization setting. Dis Manag \& Health Outcomes 2003; 11: $663-671$.
24. Bjerrum L, Cots JM, Llor C, et al. Effect of intervention promoting a reduction in antibiotic prescribing by improvement of diagnostic procedures: a prospective, before and after study in general practice. Eur J Clin Pharmacol 2006; 62(11): 913-918

25. Briel M, Langewitz W, Tschudi $P$, et al. Communication training and antibiotic use in acute respiratory tract infections: a cluster-randomised controlled trial in general practice. Swiss Med Wkly 2006; 136(15-16): 241-247.

26. Briel M, Schuetz $\mathrm{P}$, Mueller B, et al. Procalcitonin-guided antibiotic use vs a standard approach for acute respiratory tract infections in primary care. Arch Intern Med 2008; 168(18): 2000-2007.

27. Bryars $\mathrm{CH}$ 3rd, deGruy FV, Dickinson LC, et al. The effects of the rapid strep test on physician management of streptococcal pharyngitis. J Am Board Fam Pract 1991; 4(3): 139-143.

28. Cals JW, Butler CC, Hopstaken RM, et al. Effect of point of care testing for $C$ reactive protein and training in communication skills on antibiotic use in lower respiratory tract infections: cluster randomised trial. BMJ 2009; 338: b1374.

29. Christakis DA, Zimmerman FJ, Wright JA, et al. A randomized controlled trial of point-of-care evidence to improve the antibiotic prescribing practices for otitis media in children. Pediatrics 2001; 107(2): E15.

30. Coenen S, Van Royen P, Michiels B, et al. Optimizing antibiotic prescribing for acute cough in general practice: a cluster-randomized controlled trial. $J$ Antimicrob Chemother 2004; 54(3): 661-672.

31. Cox CM, Jones M. Is it possible to decrease antibiotic prescribing in primary care? An analysis of outcomes in the management of patients with sore throats. Fam Pract 2001; 18(1): 9-13.

32. Davis RL, Wright J, Chalmers F, et al. A cluster randomized clinical trial to improve prescribing patterns in ambulatory pediatrics. PLoS Clin Trials 2007: 2(5): e25.

33. De Santis G, Harvey KJ, Howard D, et al. Improving the quality of antibiotic prescription patterns in general practice. The role of educational intervention. Med J Aust 1994; 160(8): 502-505.

34. Diederichsen HZ, Skamling M, Diederichsen A, et al. Randomised controlled trial of CRP rapid test as a guide to treatment of respiratory infections in general practice. Scand J Prim Health Care 2000; 18(1): 39-43.

35. Finkelstein JA, Davis RL, Dowell SF, et al. Reducing antibiotic use in children: A randomized trial in 12 practices. Pediatrics 2001; 108(1): 1-7.

36. Flottorp S, Oxman AD, Havelsrud K, et al. Cluster randomised controlled trial of tailored interventions to improve the management of urinary tract infections in women and sore throat. BMJ 2002; 325(7360): 367-370.

37. Friis $\mathrm{H}, \mathrm{Bro} F$, Mabeck CE, et al. Changes in prescription of antibiotics in general practice in relation to different strategies for drug information. Dan Med Bull 1991; 38(4): 380-382.

38. Gonzales R, Steiner JF, Lum A, et al. Decreasing antibiotic use in ambulatory practice: impact of a multidimensional intervention on the treatment of uncomplicated acute bronchitis in adults. JAMA 1999; 281(16): 1512-1519.

39. Gonzales R, Sauaia A, Corbett KK, et al. Antibiotic treatment of acute respiratory tract infections in the elderly: effect of a multidimensional educational intervention. J Am Geriatr Soc 2004; 52(1): 39-45.

40. González OE, Armas PL, Bravo G Jr, et al. Prescription of antibiotics for mild acute respiratory infections in children. Bull Pan Am Health Organ 1996; 30(2): 106-117.

41. Greene RA, Beckman H, Chamberlain J, et al. Increasing adherence to a community-based guideline for acute sinusitis through education, physician profiling, and financial incentives. Am J Manag Care 2004; 10(10): 670-678.

42. Guillemot D, Varon E, Bernede C, et al. Reduction of antibiotic use in the community reduces the rate of colonization with penicillin $\mathrm{G}$-nonsusceptible Streptococcus pneumoniae. Clin Infect Dis 2005; 41(7): 930-938.

43. Harris RH, Mackenzie TD, Leeman-Castillo B, et al. Optimizing antibiotic prescribing for acute respiratory tract infections in an urban urgent care clinic. J Gen Intern Med 2003; 18(5): 326-334.

44. Hennessy TW, Petersen KM, Bruden D, et al. Changes in antibioticprescribing practices and carriage of penicillin-resistant Streptococcus pneumoniae: a controlled intervention trial in rural Alaska. Clin Infect Dis 2002; 34(12): 1543-1550.

45. Hickman DE, Stebbins MR, Hanak JR, et al. Pharmacy-based intervention to reduce antibiotic use for acute bronchitis. Ann Pharmacother 2003; 37(2): 187-191.

46. Hueston WJ, Mainous AG, Brauer N, et al. Evaluation and treatment of 
respiratory infections: Does managed care make a difference? J Fam Pract 1997; 44(6): 572-577.

47. Ilett KF, Johnson S, Greenhill G, et al. Modification of general practitioner prescribing of antibiotics by use of a therapeutics adviser (academic detailer). Br J Clin Pharmacol 2000; 49(2): 168-173.

48. Juzych NS, Banerjee M, Essenmacher $L$, et al. Improvements in antimicrobial prescribing for treatment of upper respiratory tract infections through provider education. J Gen Intern Med 2005; 20(10): 901-905

49. Malmvall BE, Molstad S, Darelid J, et al. Reduction of antibiotics sales and sustained low incidence of bacterial resistance: report on a broad approach during 10 years to implement evidence-based indications for antibiotic prescribing in Jonkoping County, Sweden. Qual Manag Health Care 2007; 16(1): 60-67.

50. Margolis CZ, Warshawsky SS, Goldman L, et al. Computerized algorithms and pediatricians' management of common problems in a community clinic. Acad Med 1992; 67(4): 282-284.

51. Martens JD, Werkhoven MJ, Severens JL, et al. Effects of a behaviour independent financial incentive on prescribing behaviour of general practitioners. J Eval Clin Pract 2007; 13(3): 369-373.

52. Mclsaac WJ, Goel V, To T, et al. Effect on antibiotic prescribing of repeated clinical prompts to use a sore throat score: lessons from a failed community intervention study. J Fam Pract 2002; 51(4): 339-344.

53. Melander E, Bjorgell A, Bjorgell P, et al. Medical audit changes physicians' prescribing of antibiotics for respiratory tract infections. Scand J Prim Health Care 1999; 17(3): 180-184.

54. Molstad S, Hovelius B. Reduction in antibiotic usage following an educational programme. Fam Pract 1989; 6(1): 33-37.

55. Molstad S, Ekedahl A, Hovelius B, et al. Antibiotics prescription in primary care: a 5-year follow-up of an educational programme. Fam Pract 1994; 11(3): 282-286.

56. Munck AP, Gahrn-Hansen B, Sogaard P, et al. Long-lasting improvement in general practitioners' prescribing of antibiotics by means of medical audit. Scand J Prim Health Care 1999; 17(3): 185-190.

57. O'Connor PJ, Amundson G, Christianson J. Performance failure of an evidence-based upper respiratory infection clinical guideline. J Fam Pract 1999; 48(9): 690-697.

58. Perez-Cuevas R, Guiscafre H, Munoz O, et al. Improving physician prescribing patterns to treat rhinopharyngitis. Intervention strategies in two health systems of Mexico. Soc Sci Med 1996; 42(8): 1185-1194.

59. Perz JF, Craig AS, Coffey CS, et al. Changes in antibiotic prescribing for children after a community-wide campaign. JAMA 2002; 287(23): 3103-3109.

60. Poses RM, Cebul RD, Wigton RS. You can lead a horse to water - improving physicians' knowledge of probabilities may not affect their decisions. Med Decis Making 1995; 15(1): 65-75.

61. Rautakorpi UM, Huikko S, Honkanen P, et al. The antimicrobial treatment strategies (MIKSTRA) program: a 5-year follow-up of infection-specific antibiotic use in primary health care and the effect of implementation of treatment guidelines. Clin Infect Dis 2006; 42(9): 1221-1230.

62. Raz R, Porat V, Ephros M. Can an educational program improve the diagnosis and treatment of pharyngotonsillitis in the ambulatory care setting? Isr J Med Sci 1995; 31(7): 432-435

63. Razon Y, Ashkenazi S, Cohen A, et al. Effect of educational intervention on antibiotic prescription practices for upper respiratory infections in children: a multicentre study. J Antimicrob Chemother 2005; 56(5): 937-940.

64. Rubin MA, Bateman $\mathrm{K}, \mathrm{Alder} \mathrm{S}$, et al. A multifaceted intervention to improve antimicrobial prescribing for upper respiratory tract infections in a small rural community. Clin Infect Dis 2005; 40(4): 546-553.
65. Smabrekke L, Berild D, Giaever A, et al. Educational intervention for parents and healthcare providers leads to reduced antibiotic use in acute otitis media. Scand J Infec Dis 2002; 34(9): 657-659.

66. Smeets HM, Kuyvenhoven MM, Akkerman AE, et al. Intervention with educational outreach at large scale to reduce antibiotics for respiratory tract infections: a controlled before and after study. Fam Pract 2009; 26(3): 183-187.

67. Sondergaard J, Andersen M, Stovring H, et al. Mailed prescriber feedback in addition to a clinical guideline has no impact: a randomised, controlled trial. Scand J Prim Health Care 2003; 21(1): 47-51.

68. Strandberg EL, Ovhed I, Troein M, et al. Influence of self-registration on audit participants and their non-participating colleagues: a retrospective study of medical records concerning prescription patterns. Scand J Prim Health Care 2005; 23(1): 42-46.

69. Temte JL, Shult PA, Kirk CJ, et al. Effects of viral respiratory disease education and surveillance on antibiotic prescribing. Fam Med 1999; 31(2): 101-106.

70. Touzet S, Refabert L, Letrilliart L, et al. Impact of consensus development conference guidelines on primary care of bronchiolitis: are national guidelines being followed? J Eval Clin Pract 2007; 13(4): 651-656.

71. Van Driel ML, Coenen S, Dirven K, et al. What is the role of quality circles in strategies to optimise antibiotic prescribing? A pragmatic cluster-randomised controlled trial in primary care. Qual Saf Health Care 2007; 16(3): 197-202.

72. Varonen H, Rautakorpi UM, Nyberg S, et al. Implementing guidelines on acute maxillary sinusitis in general practice: a randomized controlled trial. Fam Pract 2007; 24(2): 201-206.

73. Welschen I, Kuyvenhoven MM, Hoes AW, et al. Effectiveness of a multiple intervention to reduce antibiotic prescribing for respiratory tract symptoms in primary care: randomised controlled trial. BMJ 2004; 329(7463): 431.

74. Zwar N, Wolk J, Gordon J, et al. Influencing antibiotic prescribing in general practice: a trial of prescriber feedback and management guidelines. Fam Pract 1999; 16(5): 495-500

75. Zwar NA, Gordon JJ, Sanson-Fisher RW. Evaluation of an educational program in rational prescribing for GP trainees. Aust Fam Physician 1995; 24(5): 833-838.

76. Van Tulder M, Furlan A, Bombardier C, et al. Updated method guidelines for systematic reviews in the Cochrane collaboration back review group. Spine 2003; 28(12): 1290-1299.

77. Huttner B, Goosens H, Verheij T, et al. Characteristics and outcomes of public campaigns aimed at improving the use of antibiotics in outpatients in highincome countries. Lancet Infect Dis 2010; 10(1): 17-31.

78. Thoolen B, de Ridder D, van Lensvelt-Mulders G. Patient-oriented interventions to improve antibiotic prescribing practices in respiratory tract infections: a meta-analysis. Health Psychology Review 2011; DOI:10.1080/1743. 7199.2011.552061.

79. Van Duijn HJ, Kuyvenhoven MM, Schellevis FG, et al. Illness behaviour and antibiotic prescription in patients with respiratory tract symptoms. $\mathrm{Br} J \mathrm{Gen}$ Pract 2007; 57(540): 561-568.

80. Butler CC, Rollnick S, Pill R, et al. Understanding the culture of prescribing: qualitative study of general practitioners' and patients' perceptions of antibiotics for sore throat. BMJ 1998; 317(7159): 637-642.

81. Petursson P. GPs' reasons for 'non-pharmacological' prescribing of antibiotics. A phenomenological study. Scand J Prim Health Care 2005; 23(2): 120-125.

82. Francis NA, Butler CC, Hood K, et al. Effect of using an interactive booklet about childhood respiratory tract infections in primary care consultations on reconsulting and antibiotic prescribing: a cluster randomised controlled trial. BMJ 2009; 339: b2885 